\title{
Atypical Presentation of Herpes Simplex Virus 1 Encephalitis in Pediatric Age
}

\author{
Carmen Gulizia ${ }^{1}$, Pierluigi Smilari ${ }^{1}$, Filippo Greco ${ }^{1}$, Alessandra Fontana ${ }^{1}$, Manuela Ceccarelli ${ }^{2,3 *}$ (iD), Emmanuele Venanzi Rullo ${ }^{4}$, \\ Giuseppe Nunnari ${ }^{4}$, Piero Pavone ${ }^{1}$ \\ ${ }^{1}$ Department of Clinical and Experimental Medicine, Section of Paediatrics and Child Neuropsychiatry, University of Catania, \\ Catania, Italy; ${ }^{2}$ Department of Clinical and Experimental Medicine, Unit of Infectious Diseases, University of Catania, Catania, \\ Italy; ${ }^{3}$ Department of Biomedical, Dental, Morphological and Functional Imaging Sciences, Unit of Infectious Diseases, \\ University of Messina, Catania, Catania, Italy; ${ }^{4}$ Department of Clinical and Experimental Medicine, Unit of Infectious Diseases, \\ University of Messina, Catania, Italy
}

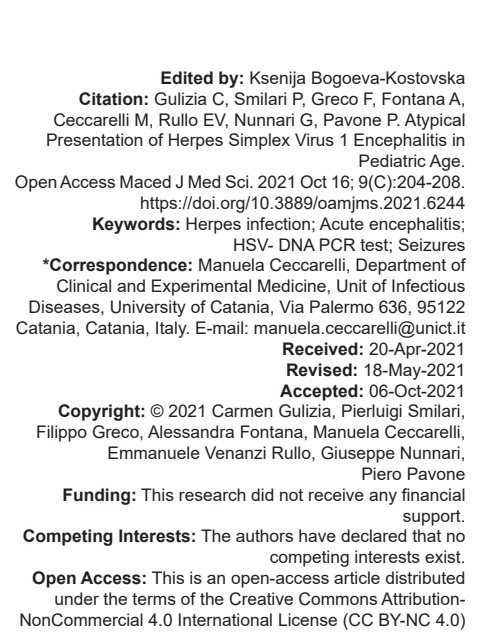

\section{Abstract}

BACKGROUND: The annual incidence of herpes simplex encephalitis (HSE) is 1:250-500 thousand in developed countries, which makes it the most common viral cause of encephalitis. Encephalitis caused by HSV-1 probably accounts for most of the cases in the Herpesviridae family and typically affects older children.

CASE REPORT: An atypical presentation of pediatric herpetic encephalitis is reported. The child presented with recurrent seizures that were initially unresponsive to several anticonvulsant drugs. EEG and MRI of the brain were not effective for diagnosis. PCR analysis of the cerebrospinal fluid indicated positivity for HSV DNA and was crucial for the diagnosis as a highly sensitive and specific test.

CONCLUSION: Based on the clinical presentation of the child, viral encephalitis was deemed to be the most likely aetiological condition

\section{Introduction}

Herpes simplex virus 1 (HSV-1) encephalitis is an acute necrotizing brain infection that generally affects the frontal or temporal cortex and the limbic system [1]. In children, it can be a serious condition, and its outcome is mainly dependent on early diagnosis and the prompt start of treatment. The annual incidence of herpes simplex encephalitis (HSE) is 1:250-500 thousand in developed countries, which makes it the most common viral cause of encephalitis [2]. Encephalitis caused by HSV-1 probably accounts for most of the cases in the Herpesviridae family and typically affects older children. Herpes simplex virus is an enveloped double-stranded DNA virus and is generally categorized as HSV-1 and HSV-2. Both of them can affect the central nervous system and can replicate in the neuronal cells in a phenomenon known as neurovirulence [2].
A relevant characteristic of the herpes virus is its latency. Reactivation of latent HSV can occur after various insults, such as fever, trauma, and infections [3]. Possible clinical manifestations are fever, headache, neck stiffness, nausea, vomiting, seizures, and an altered state of consciousness. A lesion involving a specific brain area can result in other symptoms, such as anosmia, aphasia, language dysfunctions, hallucinations, and focal convulsions. Cerebrospinal fluid (CSF) could be useful as a diagnostic tool. The gold standard diagnostic test for HSE is the HSV DNA polymerase chain reaction (PCR), which is highly sensitive and specific [2].

We present this case report of a 2-year-old girl with fever and seizures, diagnosed as HSE, who showed an early relapse with no organic sign of disease except for seizures. We also discuss the case along with the available literature. 


\section{Case Report}

A 2-year-old girl came to the Paediatric Department of the University of Catania for consultation. She was referred by a nearby hospital due to high temperature and clonic tonic seizures that responded poorly to benzodiazepine and other anticonvulsant drugs. Despite a continuous intravenous (iv) infusion of midazolam and oral valproic acid, the patient continued to present clonic tonic seizures with drooling and perioral cyanosis at every attempt to stop benzodiazepine treatment.

Electroencephalogram (EEG) showed slow theta and theta-delta intercritical activity that was widespread without a clear focus. The brain MRI resulted non-specific. At admission, the patient had poor general condition with normal temperature, a heart rate of $105 \mathrm{bpm}$, oxygen saturation of $100 \%$, and no signs of meningeal involvement. The rest of the physical evaluation was also unremarkable. Upon neurological examination, she presented slightly clouded sensory perception, followed by phases of agitation and poorly structured language.

Therapy with acyclovir was immediately started due to a suspicion of viral encephalitis when considering the recurring trend of critical episodes. A PCR test for HSV-1 of the CSF was performed, resulting positive, and diagnosis of HSE was made. Treatment with acyclovir $(65 \mathrm{mg} / \mathrm{kg} /$ day iv every $8 \mathrm{~h}$ for 30 days) and ceftriaxone (100 mg/kg/day iv every $12 \mathrm{~h}$ for 10 day) was continued. During hospitalization, the patient underwent numerous EEGs, which did not show typical epileptiform anomalies. Anti-HSV-1 immunoglobulins IgM and IgG were absent. There was no hyponatremia. Anti-neuronal and anti-myelin oligodendrocyte glycoprotein antibodies were absent from the CSF.

The metabolic test, serum amino acid, serum ammonia, and blood lactic acid were also normal. Lymphocyte subpopulations were normal. The patient also underwent an electrocardiogram, cardiac ultrasound, and eye examinations, which were normal. The child continued to present seizures, so add-on iv levetiracetam was started, which resulted in a progressive resolution of the critical episodes and a gradual weaning of midazolam infusion. The result of a brain MRI at 3 weeks after the onset of symptoms was unremarkable. Furthermore, a few days later, a new lumbar puncture showed the absence of HSV-1 DNA. Clinical symptoms improved progressively until the complete disappearance of seizures under anticonvulsant treatment. The patient was discharged in good general condition with the following therapy: valproic acid at $11 \mathrm{mg} / \mathrm{kg}$ every 8 hours, levetiracetam at $20 \mathrm{mg} / \mathrm{kg}$ every $12 \mathrm{~h}$, and micro B6 drops.

About 2 weeks after discharge, the child presented a new episode of fever and generalized clonic-tonic seizures, so she was hospitalized again. Anticonvulsant therapy and midazolam in continuous infusion were performed until the seizures resolved. The results of EEG were unremarkable again. The patient was discharged and is undergoing monthly clinical follow-up. Anticonvulsant treatment is still continuing. At the 6-month follow-up, no new episodes of seizures or fever were recorded.

\section{Discussion}

HSE typically presents as a febrile syndrome accompanied by seizures, alterations of the conscious level, focal neurologic signs and progressive deterioration. However, especially in children younger than 2 years of age, the clinical picture may be more non-specific [4].

In our case, a 2-year-old girl presented at the emergency room with a typical encephalitic syndrome, HSE was immediately suspected, and the treatment was promptly started. EEG and MRI showed nonspecific signs; however, PCR test resulted positive for HSV-1.

Viral encephalitis is a medical emergency and the most common cause of sporadic fatal encephalitis in patients older than 6 months of age in the Western world [5]. It is a complex neurological syndrome caused by inflammation of the brain parenchyma. It is often rapidly progressive, and a wide number of etiological agents are involved [6]. The causes of encephalitis can be broadly categorized as infections, immunemediated (or inflammatory), or unknown. Globally, the three most common causes of infectious encephalitis in children are HSV, varicella-zoster virus (VZV), and enterovirus [7], [8].

HSE is a life-threatening consequence of HSV infection of the central nervous system and is regarded as the most common cause of sporadic fatal encephalitis in patients $>6$ months of age in the Western world. Untreated HSE has a mortality rate of $70 \%$ in adults, with $<3 \%$ of patients returning to normal function [5]. Survival rates are improved if treatment is started within 4 days after the onset of the illness [9]. $\mathrm{HSV}$ is a ubiquitous human pathogen that causes a wide spectrum of illnesses ranging from minor clinical signs to severe complications such as encephalitis [10]. Most childhood cases of HSV-1 infection are caused by oral transmission [4], [11], [12], [13], [14], [15]. The involvement of neural tissue results in either latency or the destruction of neurons and glial cells. Disruption of the blood-brain barrier (BBB) is an important pathological mechanism for the development of HSE. The specific mechanism underlying the BBB destruction remains unclear, but the Golgi apparatus (GA) plays a crucial role in maintaining the integrity of the BBB [16]. 
An important characteristic of herpes viruses is their latency. Following primary infection of the epithelial cells with HSV, the virus enters the sensory neurons and is transported to the sensory ganglia, where it becomes latent and lies quiescent through mechanisms that are poorly understood [3]. Reactivation of latent HSV can occur after several insults such as fever, infection, trauma, and immunodeficiency. Thus, an individual infected with HSV is always a potential reservoir of infectious virus [3].

The most common symptoms in the clinical presentation of HSE in children are altered mental status, dysphasia, fever, headache, irritability, seizure, and visual field defects [17]. Hyponatremia (<135 mEq/l) is a peculiar laboratory parameter, so the presence of hyponatremia among patients with viral encephalitis could be helpful for the early diagnosis of HSE before CSF PCR results become available [18]. The prognosis for patients with this condition depends on correct and immediate diagnosis and the introduction of appropriate treatment to decrease the extent of permanent brain damage [19]. Medical history, physical examination, characteristics of clinical symptoms, and an analysis of the CSF are very important for the diagnosis.

The detection of HSV 1 in the CSF through PCR is the gold standard diagnostic test for HSE. PCR has $94 \%$ sensitivity and $98 \%$ specificity compared with HSV culture from brain biopsy [20]. However, PCR has supplanted viral culture and brain biopsy for the identification of HSV infections of the central nervous system in children [21]. Other important diagnostic tests are brain MRI and EEG [22], although they were not useful in this case.

The spectrum of imaging abnormalities in HSE includes edema, hemorrhage, and necrosis. The involvement of the inferior frontal and infero-medial temporal lobes and insular cortex leads to a hypothesis that the infection's way into the brain follows the small branches of the trigeminal nerve [23]. Abnormalities occur in the temporal lobe in $80 \%$ of patients, and $10 \%$ have extra-temporal abnormalities [7], [8]. Computed tomography (CT) of the head may also be useful, but it is less sensitive than MRI. The results of EEG are abnormal in $80 \%$ of patients with HSE and usually show periodic lateralizing epileptiform discharges in the temporal lobe [24].

Early detection and diagnosis of HSV1 encephalitis is crucial as the prompt administration of acyclovir within 4 days after the onset of the illness can dramatically reduce both morbidity and mortality [19]. Acyclovir is the most extensively studied inhibitor of HSV replication [3]. Intravenous acyclovir is the mainstay of treatment. The current recommended dose is $45 \mathrm{mg} /$ $\mathrm{kg}$ per day in 3 divided doses for children and $60 \mathrm{mg} / \mathrm{kg}$ per day in 3 divided doses for neonates [2]. However, it is ineffective against latent infection and does not eradicate the virus from the ganglia. The standard of care in the past decade has seen an increase in the duration of treatment from 14 days to 21 days [24].
This approach has shown a lower incidence of adverse neurological outcomes.

Early relapse of HSE has been firstly described in 1984. Since then, several cases were published in literature. However, the exact prevalence is still unknown [15]. In our case, the young patient showed again signs and symptoms of HSE after 14 days from first being discharged, despite the acyclovir treatment. The majority of relapses syndromes appear during the first month from the onset of symptoms, following a successful treatment with acyclovir.

Maia et al. [15] published in 2010 the case of a 7-month-old boy with an HSE relapse which was related to a deficiency of UNC93B and TLR3. Therefore, relapses might be related to an immunological dysfunction.

In our case, there were no reasons to suspect an immune system impairment of the child. Therefore, we did not perform detailed studies of the immune response. Specific IgM and IgG tested negative, but it has been demonstrated that seroconversion might happen after 10-15 days from the onset of symptoms; since the serum sample was taken around the time of the onset of symptoms, negativity of this test is not suggestive.

\section{Conclusions}

Based on the clinical presentation of the child, viral encephalitis was deemed to be the most likely aetiological condition. Early diagnosis and treatment are very important for this serious disease. The outcome was characterized by early-onset epileptic encephalopathy with relapses and a poor response to antiepileptic treatment. The fever probably triggered the reactivation of an asymptomatic HSV-1 infection and manifested with recurrent seizures. Another feature is the absence of specific HSE abnormalities in the results of EEG and MRI, as well as a normal evaluation in the neurological examination.

\section{Acknowledgments}

The authors would like to thank AME for the English language review. Certificate Verification Key: 744-574-569-834-771.

We confirm that we have read the journal's guidelines on issues involving ethical publication and affirm that this report is coherent with these guidelines.

A plagiarism check has been done with Small SEO tools: https://smallseotools.com/it/ plagiarism-checker. 


\section{Availability of Data and Material}

Data about the clinical case are available at the corresponding author.

\section{Consent for Publication}

The parents of the child signed an informed consent for the publication of this case.

\section{References}

1. Britton PN, Dale RC, Booy R, Jones CA. Acute encephalitis in children: Progress and priorities from an Australasian perspective. J Paediatr Child Health. 2015;51(2):147-58. http:// doi.org/10.1111/jpc.12650

PMid:24953748

2. Alsweed A, Alsuhibani M, Casanova JL, Al-Hajjar S. Approach to recurrent Herpes Simplex Encephalitis in children. Int J Pediatr Adolesc Med. 2018;5(2):35-8. http://doi.org/10.1016/j. ijpam.2018.05.004

PMid:30805531

3. Kesson AM. Use of aciclovir in herpes simplex virus infections. J Paediatr Child Health. 1998;34(1):9-13. http://doi. org/10.1046/j.1440-1754.1998.00440.x

PMid:9568933

4. García-Ribes A, Martínez-González MJ, Prats-Viñas JM Suspected herpes encephalitis and opercular syndrome in childhood. Pediatr Neurol. 2007;36(3):202-6. http://doi. org/10.1016/j.pediatrneurol.2006.10.006

PMid:17352959

5. Elbers JM, Bitnun A, Richardson SE, Ford-Jones EL, Tellier R, Wald RM, et al. A 12-year prospective study of childhood herpes simplex encephalitis: Is there a broader spectrum of disease? Pediatrics. 2007;119(2):e399-407. http://doi.org/10.1542/ peds.2006-1494

PMid:17272602

6. Granerod J, Crowcroft NS. The epidemiology of acute encephalitis. Neuropsychol Rehabil. 2007;17(4-5):406-28. http://doi.org/10.1080/09602010600989620

PMid: 17676528

7. Whitley RJ. Herpes simplex encephalitis: Adolescents and adults. Antiviral Res. 2006;71(2-3):141-8. http://doi. org/10.1016/j.antiviral.2006.04.002

PMid:16675036

8. Whitley RJ, Kimberlin DW. Herpes simplex encephalitis: Children and adolescents. Semin Pediatr Infect Dis. 2005;16(1):17-23. http://doi.org/10.1053/j.spid.2004.09.007 PMid:15685145

9. Whitley RJ, Gnann JW. Viral encephalitis: Familiar infections and emerging pathogens. The Lancet. 2002;359(9305):507-13. http://doi.org/10.1016/S0140-6736(02)07681-X PMid:11853816

10. Roizman B. The function of herpes simplex virus genes: $A$ primer for genetic engineering of novel vectors. Proc Natl Acad Sci U S A. 1996;93(21):11307-12. http://doi.org/10.1073/ pnas.93.21.11307

PMid:8876131

11. Schlesinger Y, Buller RS, Brunstrom JE, Moran CJ, Storch GA Expanded spectrum of herpes simplex encephalitis in childhood. J Pediatr. 1995;126(2):234-41. http://doi.org/10.1016/ s0022-3476(95)70550-3

PMid:7844669

12. Singhi P, Saini AG, Sahu JK, Kumar N, Vyas S, Vasishta RK, et al. Unusual clinical presentation and role of decompressive craniectomy in herpes simplex encephalitis. J Child Neurol. 2015;30(9):1204-7. http://doi.org/10.1177/0883073814546688 PMid:25156666

13. Silverman MS, Gartner JG, Halliday WC, Kohl S, Embree J, Kohn S. Persistent cerebrospinal fluid neutrophilia in delayedonset neonatal encephalitis caused by herpes simplex virus Type 2. J Pediatr. 1992;120(4 Pt 1):567-9. http://doi.org/10.1016/ s0022-3476(05)82485-0

PMid:1313097

14. Matsumoto S, Matsumoto E. A 20-month-old girl with fever, seizures, hemiparesis, and brain lesions requiring a diagnostic brain biopsy. Semin Pediatr Neurol. 2018;26:80-2. http://doi. org/10.1016/j.spen.2017.03.012 PMid:29961528

15. Maia R, Gouveia C, Moreira A, Casanova JL, Sancho- Shimizu V Brito MJ. Early "'relapse"' after herpetic encephalitis: Extensive white matter lesions in an infant with interferon production deficit. J Child Neurol. 2011;26(3):369-72. http://doi. org/10.1177/0883073810382140 PMid:21183725

16. He Q, Liu H, Huang C, Wang R, Luo M, Lu W. Herpes Simplex virus 1-induced blood-brain barrier damage involves apoptosis associated with GM130-mediated Golgi stress. Front Mol Neurosci. 2020;13:2. http://doi.org/10.3389/fnmol.2020.00002

17. Banerjee A, Kulkarni S, Mukherjee A. Herpes simplex virus: The hostile guest that takes over your home. Front Microbiol. 2020;11:733. http://doi.org/10.3389/fmicb.2020.00733 PMid:32457704

18. Basaran S, Yavuz SS, Bali EA, Cagatay A, Oncul O, Ozsut H, et al. Hyponatremia is predictive of HSV-1 encephalitis among patients with viral encephalitis. Tohoku J Exp Med. 2019;247(3):189-95. http://doi.org/10.1620/tjem.247.189 PMid:30890665

19. Schroth G, Gawehn J, Thron A, Vallbracht A, Voigt K. Early diagnosis of herpes simplex encephalitis by MRI. Neurology. 1987;37(2):179-83. http://doi.org/10.1212/wnl.37.2.179 PMid:3808297

20. Lakeman FD, Whitley RJ. Diagnosis of herpes simplex encephalitis: application of polymerase chain reaction to cerebrospinal fluid from brain-biopsied patients and correlation with disease. National institute of allergy and infectious diseases collaborative antiviral study group. J Infect Dis. 1995;171(4):85763. http://doi.org/10.1093/infdis/171.4.857 PMid:7706811

21. Cantey JB, Mejías A, Wallihan R, Doern C, Brock E, Salamon D, et al. Use of blood polymerase chain reaction testing for diagnosis of herpes simplex virus infection. J Pediatr. 2012;161(2):357-61. http://doi.org/10.1016/j.jpeds.2012.04.009

22. Steiner I, Budka H, Chaudhuri A, Koskiniemi M, Sainio K, Salonen $\mathrm{O}$, et al. Viral meningoencephalitis: A review of diagnostic methods and guidelines for management. Eur J Neurol. 2010;17(8):999-e57. http://doi. org/10.1111/j.1468-1331.2010.02970.x

PMid:20236175 
23. Domingues RB, Fink MC, Tsanaclis AM, de Castro CC, Cerri GG, Mayo MS, et al. Diagnosis of herpes simplex encephalitis by magnetic resonance imaging and polymerase chain reaction assay of cerebrospinal fluid. J Neurol Sci. 1998;157(2):148-53. http://doi.org/10.1016/s0022-510x(98)00069-0
PMid:9619637

24. Whitley RJ, Roizman B. Herpes simplex virus infections. Lancet. 2001;357(9267):1513-8. http://doi.org/10.1016/ S0140-6736(00)04638-9

PMid:11377626 